\title{
Nickel tungstate nanoparticles: synthesis, characterization and electrochemical sensing of mercury(II) ions
}

\author{
Hanumantharayappa Eranjaneya ${ }^{1} \cdot$ Prashanth Shivappa Adarakatti $^{2} \cdot$ Ashoka Siddaramanna $^{3}$. \\ Chandrappa Gujjarahalli Thimmanna ${ }^{1}$
}

Received: 27 September 2018 / Accepted: 24 December 2018 / Published online: 29 January 2019

(c) Springer Science+Business Media, LLC, part of Springer Nature 2019

\begin{abstract}
Nano particulate metal oxides gained significant research interest in recent years for various applications with the intension of exploring enhanced properties of miniaturization. In this research work, nickel tungstate nanoparticles $\left(\mathrm{NiWO}_{4}\right.$ nanoparticles) were successfully synthesized via a simple and efficient sucrose-nitrate decomposition method. The synthesized nanoparticles were characterized using various analytical techniques such as PXRD, SEM, TEM, BET measurements and FTIR. Transmission electron microscope images reveals the nearly spherical shaped nanoparticles of average particle size 15-35 nm. Photoluminescence characteristics of synthesized $\mathrm{NiWO}_{4}$ nanoparticles were investigated at room temperature. Further, the prepared nanoparticles were utilized as glassy carbon electrode modifier for trace level electrochemical sensing of toxic mercury present in water samples. The electrochemical behavior of mercury(II) ions at modified electrode interface has been studied by cyclic voltammetry (CV) and differential pulse stripping voltammetry (DPSV). The results illustrate that, the proposed modified GCE sensor exhibits linearity between the concentration range 10-600 nM with the limit of detection $2.25 \mathrm{nM}$ based on $3 \sigma$ method for mercury(II) ions.
\end{abstract}

\section{Introduction}

Divalent metal tungstate nanoparticles with variety of shapes have gained much attention in the field of electronics, optics, sensors, catalysis, magnetism, luminescence, drug delivery and electroanalysis [1-3]. Many of the divalent metal tungstates have also gained commercial interest in lasers and fluorescent lamps [4, 5]. Various novel and fascinating physico-chemical properties of these materials depends not

Hanumantharayappa Eranjaneya and Prashanth Shivappa Adarakatti have contributed equally.

Electronic supplementary material The online version of this article (https://doi.org/10.1007/s10854-018-00635-9) contains supplementary material, which is available to authorized users.

Chandrappa Gujjarahalli Thimmanna

gtchandrappa@yahoo.co.in

1 Department of Chemistry, Bangalore University, Bengaluru, India

2 P. G. Department of Chemistry, KLE's P. C. Jabin Science College, Vidyanagar, Hubballi, India

3 Department of Chemistry, Dayananda Sagar University, Kudlu Gate, Bengaluru, India only on degree of crystallinity but also on size and shape of nanoparticles [6]. Divalent metal tungstates of the form $\mathrm{AWO}_{4}$ are mostly crystallizes in either scheelite or wolframite structures depending on the size of $\mathrm{A}^{2+}$ ion. Among various divalent metal tungstates $\mathrm{NiWO}_{4}$ with wolframite like structure have attracted much attention due its long lasting structural stability and more importantly its electrochromic properties [7]. Also, nickel tungstate have narrow band gap and thus it has been extensively studied for visible light assisted photocatalytic applications [8-10].

Over the past few years, the development of efficient sensor with high sensitivity and low detection limit for the detection of heavy metal ions is of vital important. The discharge of heavy metal ions into the natural water bodies is increasing notably by industrial process such as electroplating, paper mills and metallurgical processes. Since these heavy metal ions are non-biodegradable in nature, presence of which in trace amounts is a serious health threat to human beings as well as aquatic life. Among heavy metals, mercury(II) is the most toxic metal which causes serious health disorders in human beings. Thus, as per the recommendation of world health organization (WHO), the threshold limit value in drinking water for mercury is $1 \mu \mathrm{g} / \mathrm{L}$ [11]. To this end, the detection of 
mercury in trace level is one of the prime requirements in the field of analytical sciences. Mercury ions can be detected by several advanced analytical techniques such as, X-ray fluorescence spectroscopy (XFS), inductively coupled plasma optical emission spectrometry, atomic absorption spectroscopy (AAS) and inductively coupled plasma mass spectrometry. However, these methods require advanced instrumentation and the process is expensive. In contrary to the above analytical techniques, electrochemical sensing enables the low cost detection of heavy metals and it requires simple instrumentation [12, 13]. In electrochemical sensing, the extent of sensitivity and the range of selectivity depends on the electrode modifier used [14, 15]. Thus, to improve the efficiency of electrode, a suitable electrode modifier is required. The electrode modifier should have enhanced electron-transfer kinetics and strong adsorption capability towards respective heavy metal ions [16]. Recent reports proves that metal oxide nanoparticles can act as good electrode modifier for the detection of heavy metal ions due to their enhanced properties as a result of miniaturization [17-21]. Metal oxides with nanosized particles will be an added advantage for sensing applications compared to their bulk counterparts owing to their enhanced surface area and catalytically active sites. Further, semiconductors with low band gap are potential candidates for sensing applications as sensitivity of the electrodes mainly depends on electron-transfer kinetics. For instance, Sivakumar et al. has been used hydrothermally synthesized $\mathrm{NiWO}_{4}$ crystals as electrode modifier for non-enzymatic glucose sensing [22]. In this regard, semiconductor $\mathrm{NiWO}_{4}$ with narrow band gap of $2.2 \mathrm{eV}$ and nano sized particles can be utilized as an electrode modifier to enhance electron-transfer kinetics and strong adsorption capability towards $\mathrm{Hg}$ (II) sensing.

Several methods have been developed to prepare phase pure $\mathrm{NiWO}_{4}$ such as, high temperature solid state synthesis $[23,24]$, co-precipitation of soluble salts in aqueous solutions [25], microwave assisted synthesis [26], microemulsion method [9], sonochemical [27] and hydrothermal method [22]. However, the reported synthetic routs are associated with many disadvantages like multistep process, long reaction time and high calcination temperatures. To this end, the development of novel synthetic method, which enables the rapid and efficient synthesis of metal oxides at nano-scale regime plays an important role. Among many techniques for the synthesis of nanoparticles through wet chemical route, combustion synthesis has several advantages (SCS) [28]. It is an effective method for the synthesis of nanoscale materials and has been used by our group for the production of various mixed metal oxides for a variety of advanced applications [29-32]. For this reason, we employed SCS method with the assistance of sucrose as fuel for the synthesis of $\mathrm{NiWO}_{4}$ nanoparticles.
In the present work, we propose a simple and cost effective solution combustion method for the synthesis of nanosize $\mathrm{NiWO}_{4}$. The synthesized nanoparticles were characterized by various analytical techniques. Further, $\mathrm{NiWO}_{4}$ nanoparticles were successfully employed as electrode modifier on glassy carbon electrode (GCE). Finally, the performance of the modified GCE was evaluated for detection of mercury ions in acetate buffer solution using differential pulse anodic stripping voltammetry (DPASV).

\section{Experimental}

\subsection{Materials and methods}

Analytical-grade sucrose, tungsten metal powder (fine powder 99+), hydrogen peroxide were obtained from MERCK limited, and nickel nitrate hexa-hydrate was obtained from S D Fine-Chem Limited. Acetic acid, sodium acetate and sodium hydroxide were purchased from SD fine Chemicals, Mumbai, India. Solutions of known $\mathrm{pH}$ in the range pH 1-12 were prepared using deionised water from MilliQ water purifier (Millipore, USA) with a resistivity of not less than $18.2 \mathrm{M} \Omega \mathrm{cm}$ at $25^{\circ} \mathrm{C}$. Stock solution of $1 \mathrm{mM}$ of mercury was prepared using AR grade mercuric bromide in Teflon volumetric flasks and stored in refrigerator. Working standards were prepared by diluting appropriate aliquots of stock solution on the day of use. Double distilled water was used in all other reagent preparations.

\subsection{Synthesis of $\mathrm{NiWO}_{4}$ nanoparticles}

Tungsten metal powder $(0.2 \mathrm{~g})$ was dissolved in $5 \mathrm{~mL}$ hydrogen peroxide solution (35\%) by heating slightly on a hot plate to obtain per-oxotungstic acid. In another beaker, $0.3163 \mathrm{~g} \mathrm{Ni}\left(\mathrm{NO}_{3}\right)_{2} \cdot 6 \mathrm{H}_{2} \mathrm{O}$ and $0.37 \mathrm{~g}$ sucrose were dissolved in $3 \mathrm{~mL}$ deionized water. Both tungsten and nickel precursor solutions were mixed together and stirred for $5 \mathrm{~min}$ to obtain homogeneous solution. The precursor mixture was concentrated by heating on hotplate to remove excess solvent. Finally, the beaker containing homogeneous sol was placed in a muffle furnace which was pre-heated at $500{ }^{\circ} \mathrm{C}$. The sol expands to form froth then it got ignited to burn with mild sparks giving voluminous powder.

\subsection{Physicochemical characterization}

Formation of phase pure product was confirmed by powder X-ray diffraction (PXRD) technique, where the PXRD patterns were recorded from PANalytical X'pert PRO MPD instrument with $\mathrm{CuK} \alpha$ radiation source of wavelength $1.541 \AA$. Surface morphologies of as obtained powder was studied by scanning electron microscopy (SEM, VEGA3 
TESCAN) and semi-quantitative elemental analyses were performed by energy-dispersive X-ray spectroscopy (EDS) in SEM chamber. High resolution transmission electron microscopy (TEM) images and selected area electron diffraction (SAED) patterns were taken on a JEOL JEM2100 instrument. Quanta Chrome Nova-1000 surface analyzer instrument was used for surface characterizations. UV-visible diffused reflectance spectrum was recorded on a Shimadzu 3101 UV-visible spectrophotometer. Fourier transform infrared spectrum (FTIR) was recorded using Bruker Alpha-P spectrometer (ATR mode, diamond crystal, $400-4000 \mathrm{~cm}^{-1}$ ). The electrochemical data was collected from Biologica SP-150 electrochemical workstation using CV, DPSV and impedance spectroscopic (EIS) techniques. A three electrode electrochemical cell with calomel, platinum wire and glassy carbon (modified and unmodified) served as reference, auxiliary, and working electrodes respectively.

\subsection{Electrode modification}

Glassy carbon electrode was used as electrode substrate which is having $3 \mathrm{~mm}$ diameter. Before the modification, the electrode surface was smoothened by different size alumina slurry such as $1,0.3$ and $0.05 \mu \mathrm{m}$ to obtain a smooth shiny surface. The electrode was washed carefully with ethanol and distilled water in a ultrasonic bath and finally dried at ambient temperature. Then the modified electrode was constructed by drop casting method by placing $10 \mu \mathrm{L}$ of aqueous colloidal suspension containing $\mathrm{NiWO}_{4}$ nanoparticles $(1 \mathrm{mg} /$ $\mathrm{mL}$ ) and it was dried at room temperature.

\subsection{Analytical procedure of electrochemical sensing}

The quantity of mercury(II) ions were measured using differential pulse anodic stripping voltammetry (DPASV). The voltammetry data was collected over the potential range -0.4 to $0.4 \mathrm{~V}$ with amplitude of $0.01 \mathrm{~V}$ and a pulse width of $0.05 \mathrm{~s}$. Specific quantity of mercury(II) solution was taken in an electrochemical cell of $10 \mathrm{~mL}$ containing $\mathrm{pH} 8$ buffer solution which is fitted with a magnetic stirrer. The modified glassy carbon electrode was immersed in the electrolyte solution of mercury ions and then stirred for $5 \mathrm{~min}$ to preconcentrate the metal ions near the interface.

The electrode was taken away from the electrochemical cell and then washed with doubly distilled water. Then the electrode was placed in another electrochemical cell which contains $0.1 \mathrm{M} \mathrm{HCl}$ and a reduction potential of $-0.4 \mathrm{~V}$ was applied for about $300 \mathrm{~s}$ to reduce all mercury ions into its atomic state and then stripped off from the surface of the electrode into bulk of solution by scanning the potential in the positive direction after $30 \mathrm{~s}$ of equilibration time.

For the sake of real sample analysis, the samples were collected from tap supply, polluted lake, treated industrial effluents, chrome plating and from textile industry. The collected analytes were filtered using Whatman filter paper to remove colloidal matter. Then known amount of filtered samples were added into electrochemical cell where, the electrolytic $\mathrm{pH}$ was maintained at 8 using phosphate buffer solution and analyzed by the procedure described as above.

\section{Results and discussion}

\subsection{Crystal structure, morphology and surface characteristics of $\mathrm{NiWO}_{4}$ nanoparticles}

Powder X-ray diffraction was used to investigate the phase structure and crystallinity of as-prepared $\mathrm{NiWO}_{4}$ and the resulting PXRD pattern is presented in Fig. 1. It is clear that all diffraction peaks could be indexed with monoclinic phase of $\mathrm{NiWO}_{4}$ and the pattern agree well with the ICDD PDF No. 72-1189. Unit cell parameters corresponding to indexed monoclinic phase were found to be $a=4.6000, b=5.6600$ and $\mathrm{c}=4.9100 \AA$ and $\beta=90.01^{\circ}$ with space group P2/c (no. 13).

The SEM images of as synthesized nanoparticles are presented in Fig. 2(a-d), which were taken at different magnifications. The images exhibit some interesting morphology with fine particulate fluffy material. From the image taken at higher magnification (Fig. 2d) one can trace nanoparticles with different sizes; however it is difficult to measure the exact particle size. Semi-quantitative elemental analysis was performed on selected area by energy dispersive X-ray spectroscopy technique in SEM chamber, which confirms the presence of $\mathrm{Ni}, \mathrm{W}$ and $\mathrm{O}$ elements. Table $\mathrm{S} 1$ summarizes the weight and atomic ratio of elements present in the

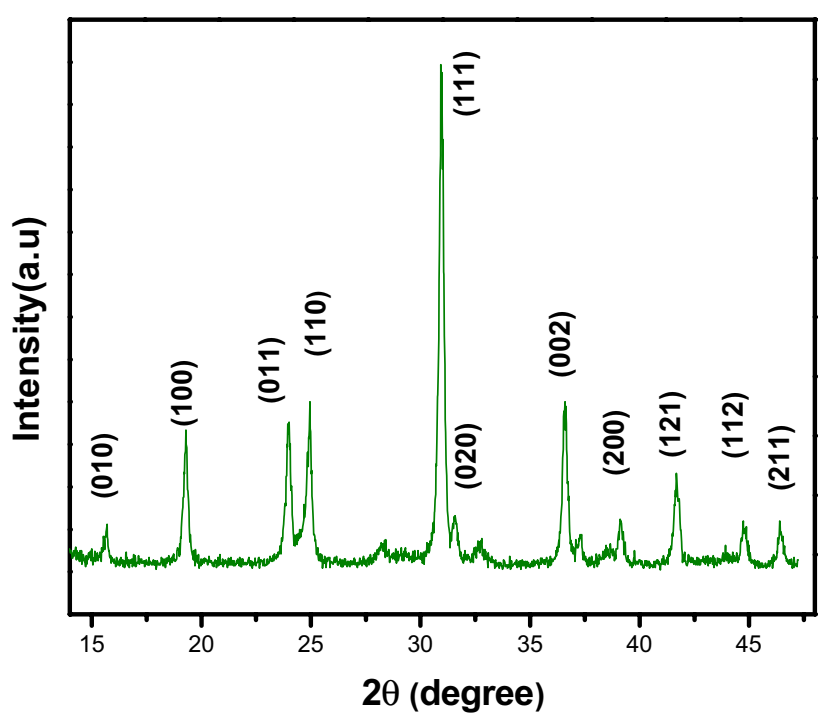

Fig. 1 The PXRD pattern of $\mathrm{NiWO}_{4}$ nanoparticles 
Fig. 2 SEM images of $\mathrm{NiWO}_{4}$ nanoparticles
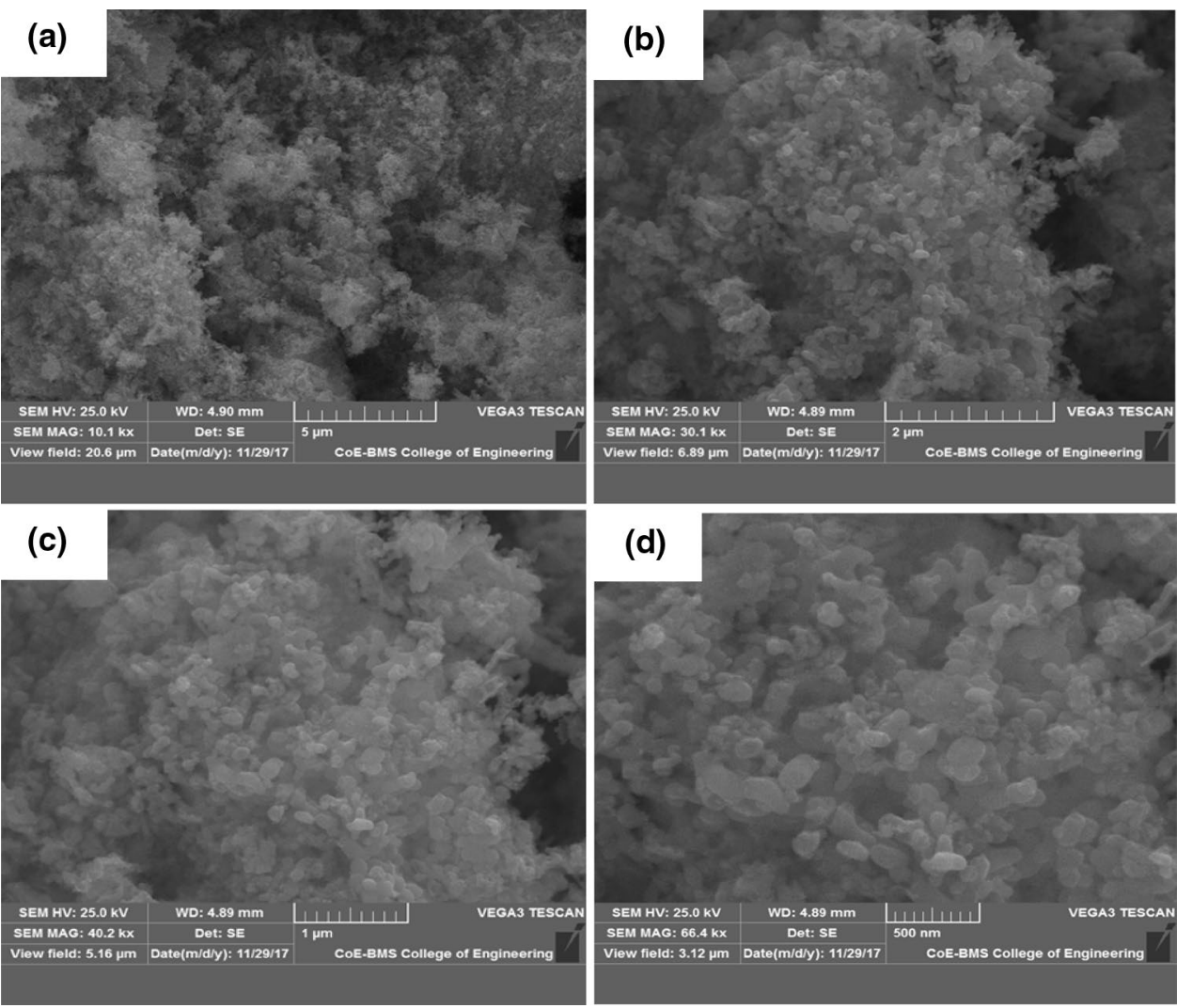

sample and the EDS spectra is given in fig. S1 in supplementary data.

Detailed morphological study has been carried out by transmission electron microscope analyses, Fig. 3(a-b) shows the TEM images of $\mathrm{NiWO}_{4}$ nanoparticles which exhibits well dispersed nearly spherical shaped nanoparticles. From TEM images the average particle size distribution has been calculated using image-J software by counting approximately 25 particles and is found to be in the range $15-35 \mathrm{~nm}$. The crystallinity of nanoparticles was tested by high resolution transmission electron microscope (HRTEM) analyses and presented in Fig. 3c. It confirms the single crystalline nature of the $\mathrm{NiWO}_{4}$ nanoparticles and the lattice spacing $0.56 \mathrm{~nm}$ correspond to inter planar distance of $(010)$ crystalline planes of monoclinic phase. Electron diffraction pattern was collected by targeting a single particle and the results are presented in Fig. 3d, where some of the bright spots were indexed with (011), (111), (200) and (121) crystalline planes based on the distance between the selected spot and transmitted spot.

In order to explore the surface characteristics such as specific surface area, pore volume, pore size and nature of porosity, nitrogen (at $77 \mathrm{~K}$ ) adsorption-desorption experiments were performed on the surface of $\mathrm{NiWO}_{4}$ nanoparticles. The adsorption-desorption isotherms have been constructed from the experimental data and presented in Fig. 4a. The sample exhibits a type IV isotherm indicating mesoporous nature and H1 type hysteresis loop. Specific surface area of the sample was calculated by BET (BrunauerEmmett-Teller) method from the adsorption data of nitrogen gas and is found to be $\sim 16 \mathrm{~m}^{2} / \mathrm{g}$. The pore size distribution curve is shown in Fig. 4b, which exhibits a predominant peak at $\sim 15 \mathrm{~nm}$ confirming the mesoporous nature. The values of pore diameter $(14.706 \mathrm{~nm})$ and pore volume $(0.069 \mathrm{cc} / \mathrm{g})$ were calculated by BJH (Barrett-Joyner-Halenda) method by using nitrogen desorption data [33].

\subsection{FTIR spectra and photoluminescence results}

The FTIR spectrum of as synthesized $\mathrm{NiWO}_{4}$ nanoparticles is shown in Fig. 5a, which further confirms the formation of pure phase. The bands appeared at 863 and $654 \mathrm{~cm}^{-1}$ could be assigned to the $\mathrm{W}-\mathrm{O}$ bond stretching and $\mathrm{O}-\mathrm{W}-\mathrm{O}$ vibrational modes respectively [8]. Further the band observed at $525 \mathrm{~cm}^{-1}$ is due to the stretching vibrations of $\mathrm{NiO}_{6}$ polyhedra in the crystal structure of $\mathrm{NiWO}_{4}$ [34]. Photoluminescence (PL) spectra have been recorded at room temperature to characterize the optical properties of $\mathrm{NiWO}_{4}$ nanoparticles. The PL excitation spectra (Fig. 5b) shows an intense peak at $430 \mathrm{~nm}$ which can be attributed to the charge transfer transition from $p$-orbital of oxygen atom to the d-orbital of $\mathrm{W}$ atom in $\mathrm{WO}_{6}$ octahedral units. The emission spectra (Fig. 5c) shows a broad peak centered at $538 \mathrm{~nm}$. 
Fig. 3 TEM images (a-b), HRTEM image (c) and SAED pattern (d) of $\mathrm{NiWO}_{4} \mathrm{NPs}$
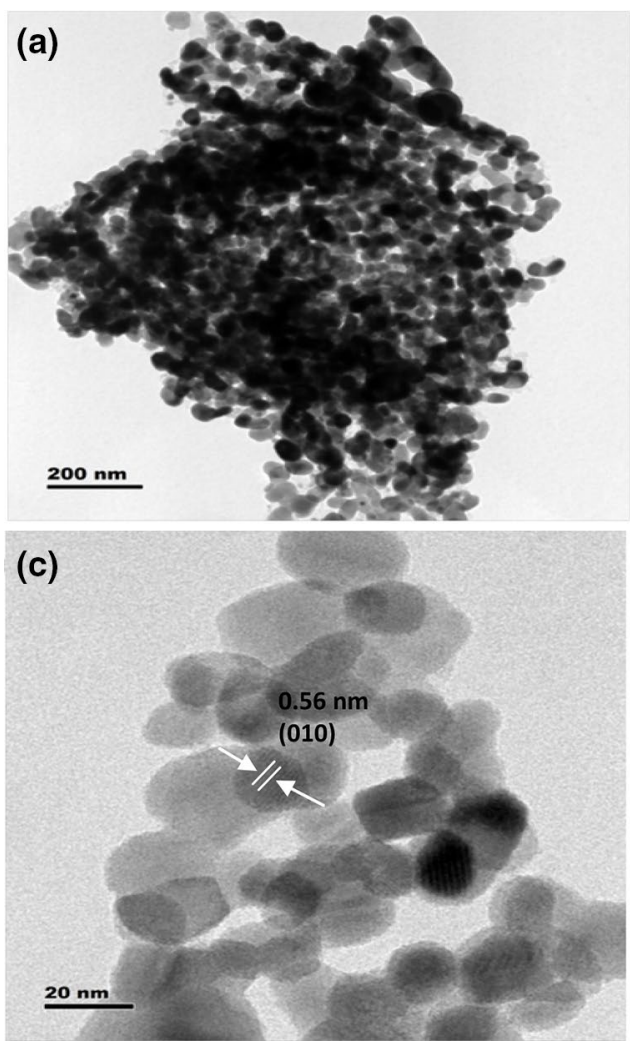

(b)
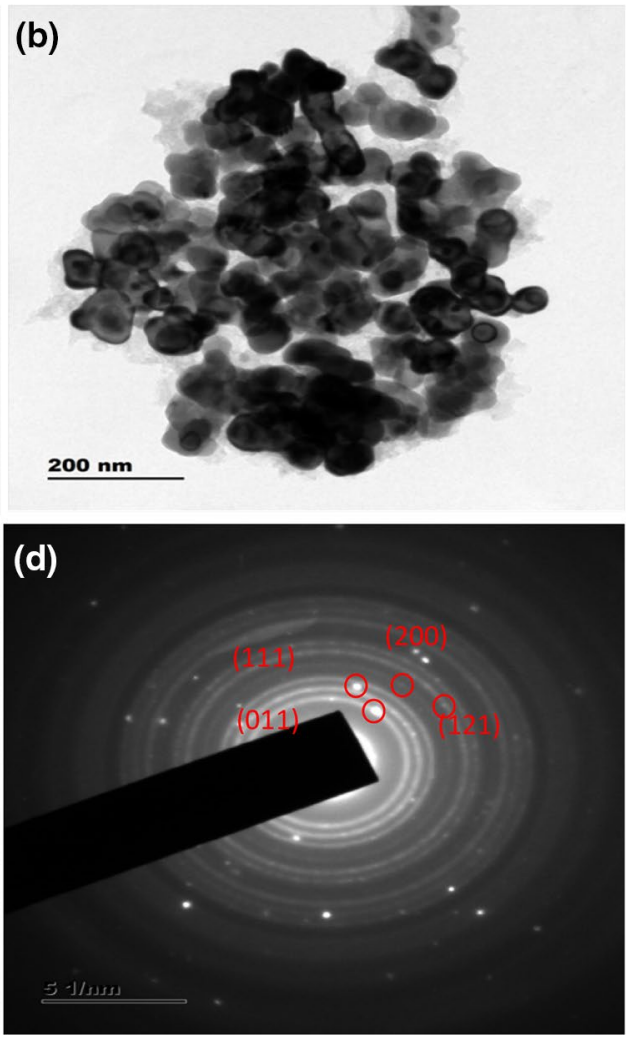
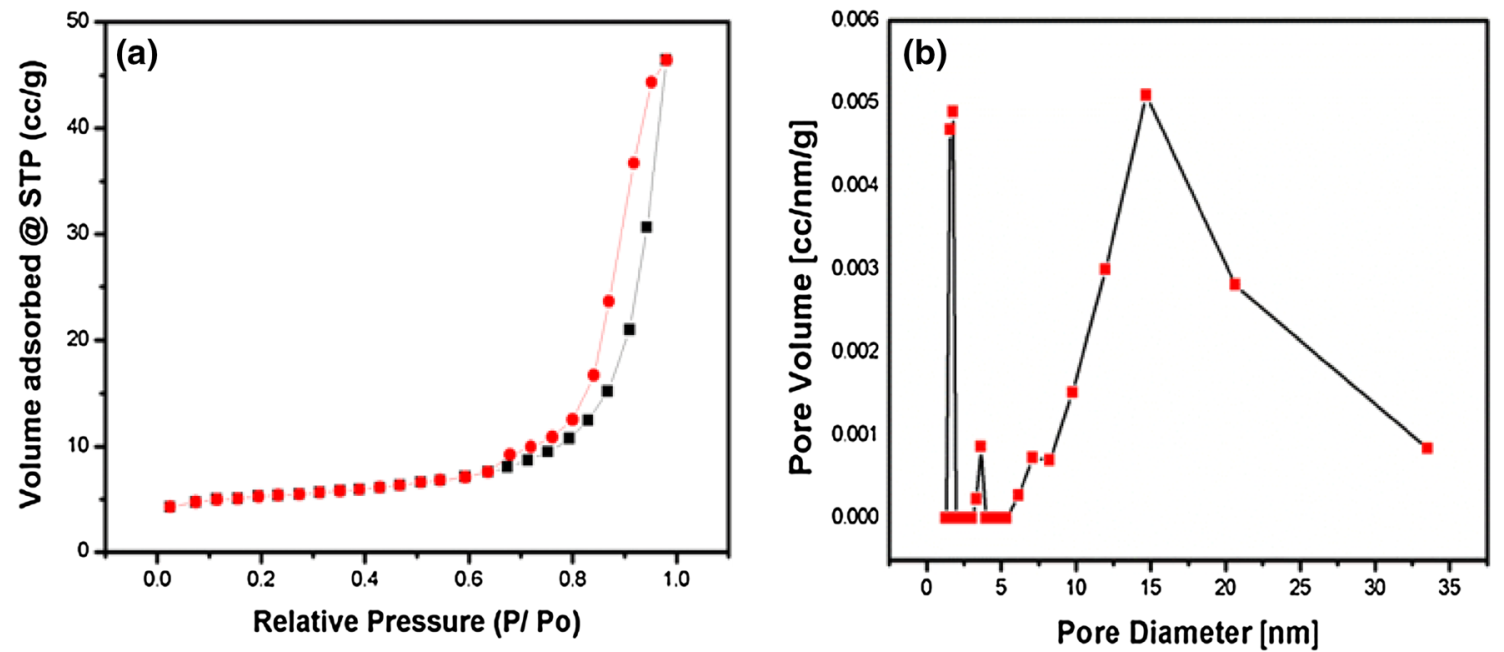

Fig. 4 Nitrogen adsorption-desorption isotherms (a), and the corresponding pore-size distribution curve (b) of $\mathrm{NiWO}_{4}$ nanoparticles

\subsection{Electrochemical behavior of modified electrode in presence of $\mathrm{Hg}(\mathrm{II})$ ions}

The electrochemical response of $\mathrm{NiWO}_{4}$ nanoparticles modified interface in presence of mercury was first examined using cyclic voltammetry in order to understand the potential affinity of the modifier material towards metal ions in solution. The typical cyclic voltammetric response in presence and in absence of mercury at $\mathrm{NiWO}_{4}$ nanoparticles modified interface in the potential window from -0.4 to $0.4 \mathrm{~V}$ is shown in Fig. 6. The modified interface did not show any peaks in the absence of mercury in the potential window used. In presence of metal ions, a voltammetric peak was observed during cathodic sweep at $0.1 \mathrm{~V}$ which can be ascribed to the two electron reduction process of $\mathrm{Hg}^{2+}$ to $\mathrm{Hg}^{0}$, where as in the reversal anodic sweep an intense 

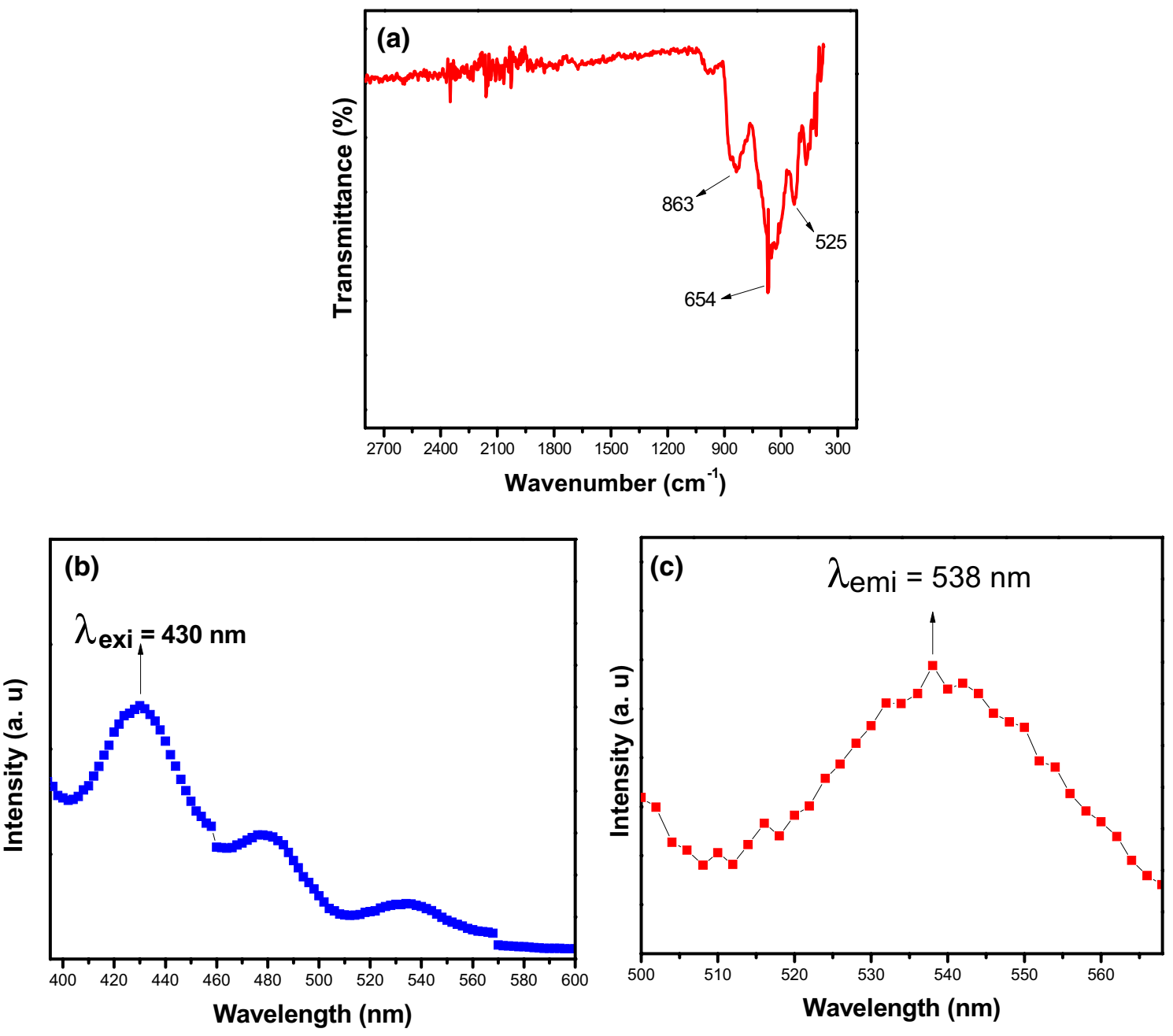

Fig. 5 a FTIR spectra, b Photoluminescence excitation, and c Photoluminescence emission spectra of $\mathrm{NiWO}_{4}$ nanoparticles

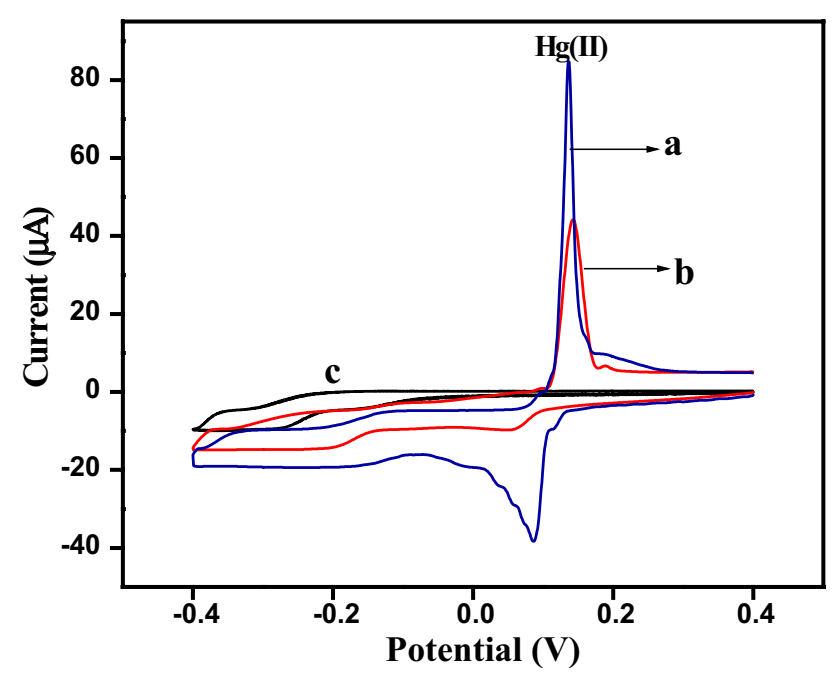

Fig. 6 Overlaid cyclic voltammograms recorded in $0.1 \mathrm{M} \mathrm{HCl}$ containing $600 \mathrm{nM}$ of $\mathrm{Hg}(\mathrm{II})$ and preconcentration time $5 \mathrm{~min}$. Modified electrode in (a) presence and (c) absence (b) bare electrode in presence of metal ion peak at $0.17 \mathrm{~V}$ was observed due to the oxidation (stripping) of $\mathrm{Hg}^{0}$ to $\mathrm{Hg}^{+}$. Such voltammetric response was not observed at unmodified interface. These studies reveal that the observed response for mercuric ion at modified interface is due to the presence of $\mathrm{NiWO}_{4}$ nanoparticles. Hence, the improved interaction of $\mathrm{NiWO}_{4}$ nanoparticles with mercury is expected to be due the presence of abundant electrocactive sites on $\mathrm{NiWO}_{4}$ nanoparticles. Therefore, modified interface can be used as a sensitive and selective sensing platform for the quantification of mercury at trace level.

\subsection{Sensing mechanism}

Initially, the $\mathrm{Hg}(\mathrm{II})$ ions adsorb on the $\mathrm{NiWO}_{4}$ nanoparticles modified electrode at open circuit potential.

$\mathrm{Hg}(\mathrm{II})+\mathrm{NiWO}_{4} \rightarrow \mathrm{NiWO}_{4}-\mathrm{Hg}(\mathrm{II})_{\text {adsorption }}$

Then, the adsorbed $\mathrm{Hg}(\mathrm{II})$ reduced to $\mathrm{Hg}(0)$ under the applied potential on the electrode surface 
$\mathrm{NiWO}_{4}-\mathrm{Hg}(\mathrm{II})_{\text {adsorption }}+2 \mathrm{e}^{-} \rightarrow \mathrm{NiWO}_{4}-\mathrm{Hg}(0)_{\text {adsorption }}$

Finally, the reduced $\mathrm{Hg}(0)$ is re-oxidized to $\mathrm{Hg}(\mathrm{II})$ during stripping into the bulk of the electrolytic solution.

$\mathrm{NiWO}_{4}-\mathrm{Hg}(0) \rightarrow \mathrm{NiWO}_{4}+\mathrm{Hg}(\mathrm{II})+2 \mathrm{e}^{-}$

\subsection{Optimization study}

In order to enhance the measurement sensitivity, the parameters influencing the analytical signal were optimized to achieve the required sensitivity. The medium $\mathrm{pH}$, deposition potential and deposition time were optimized and used in the recommended procedure.

Initially, the surface modification of glassy carbon electrode was carried out by varying with different volumes of $\mathrm{NiWO}_{4}$ nanoparticles dispersed in aqueous medium through drop coating method. Different volumes of dispersing medium were used in the range $0-25 \mu \mathrm{L}$ for drop casting on the glassy carbon electrode surface. Among all, $10 \mu \mathrm{L}$ nanoparticles suspension drop coated electrode gave a better analytical signal response (Fig. 7a). The better response at $10 \mu \mathrm{L}$ suspension is may be due to large active surface area/ sites. Thus, the $10 \mu \mathrm{L}$ volume of nanoparticles suspension was used for all further studies.

\subsection{Effect of pH}

The effect of medium $\mathrm{pH}$ (Fig. 7b) was examined in the $\mathrm{pH}$ range 3-12. It illustrates the anodic peak current in presence of $1 \mu \mathrm{M} \mathrm{Hg}^{2+}$ at different $\mathrm{pH}$ values of medium. The peak current increases with increase in the medium $\mathrm{pH}$ from 3 to 7 and almost remains constant between 7 and 10. However, the peak current decreases beyond $\mathrm{pH} 10$. As we know that, with increase in $\mathrm{pH}$, the $\mathrm{Hg}$ (II) precipitates into its hydroxide and thereby the accumulation of $\mathrm{Hg}$ (II) on the electrode surface decreases which in turn decreases anodic peak current. This shows that the $\mathrm{pH} 7$ will be optimum to get better response to wards $\mathrm{Hg}$ (II). Phosphate buffer was used to achieve the required $\mathrm{pH}$.
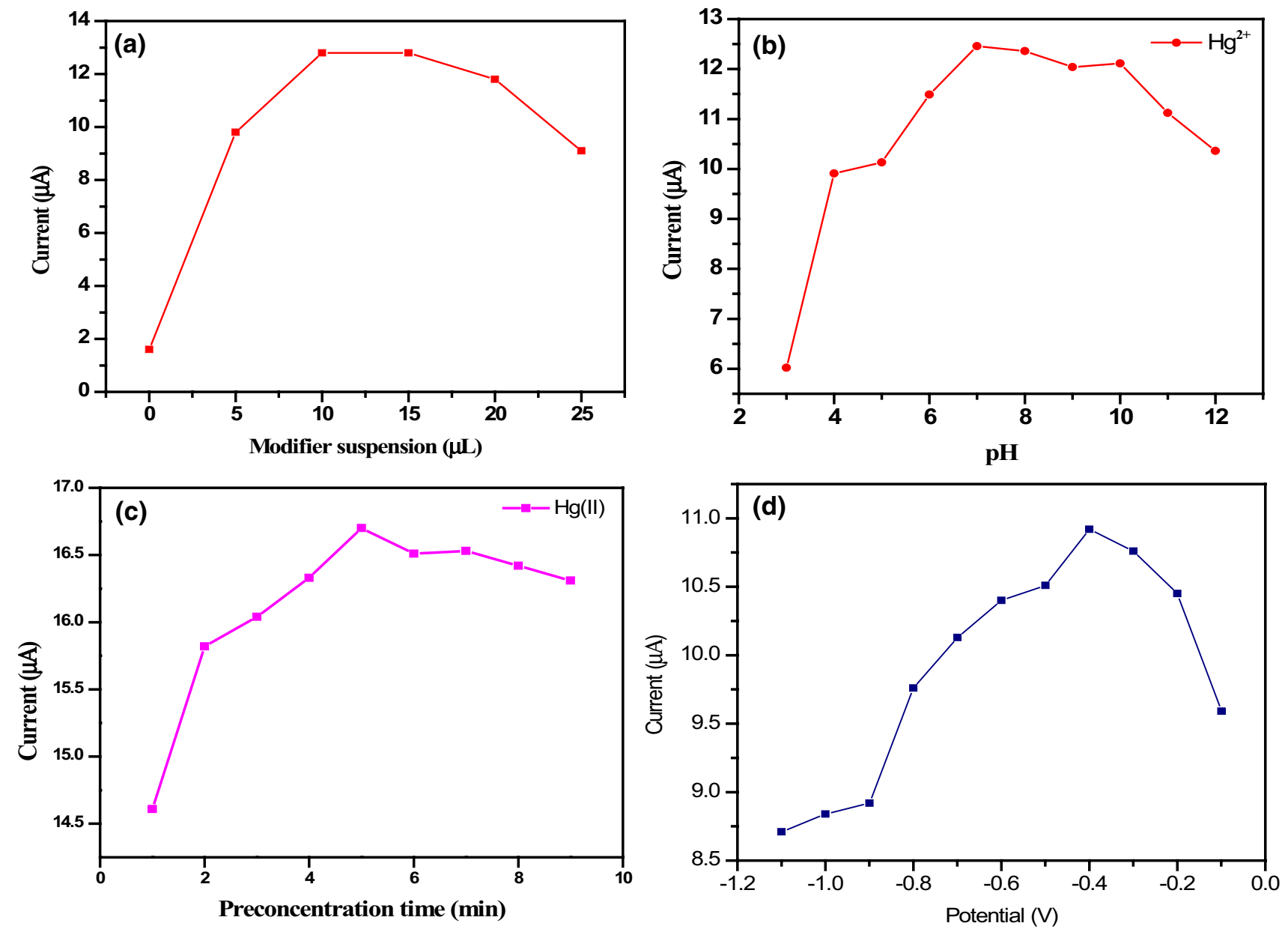

Fig. 7 a Effect of modifier volume, $\mathbf{b}$ Effect of $\mathrm{pH}, \mathbf{c}$ Effect of preconcentration time and $\mathbf{d}$ Effect of reduction potential on the anodic peak current observed for $1 \mu \mathrm{M}$ concentration of $\mathrm{Hg}^{2+}$ ion, preconcentration time $300 \mathrm{~s}$, supporting electrolyte $0.1 \mathrm{M} \mathrm{HCl}$ 


\subsection{Effect of preconcentration time}

Pre-concentration time is the time given for the $\mathrm{Hg}$ (II) to accumulate on the electrode surface and thereby plays very important role in achieving less sensing time with high sensitivity and selectivity. In the present study, effect of preconcentration time towards sensing of $\mathrm{Hg}$ (II) was studied from 1 min to 9 min (Fig. 7c) wherein the observed results indicate that the anodic peak current increases with increase in time up to $5 \mathrm{~min}$ and then starts decreasing slightly. This is because longer the pre-concentration time more and more $\mathrm{Hg}$ (II) gets accumulated on the electrode surface and thus maximum anodic peak current achieved (up to $5 \mathrm{~min}$ ). However, with further increase in pre-concentration time leads to the surface saturation and thereby active sites on the electrode surface are not available which decreases the anodic peak current. Therefore, pre-concentration time of 5 min has been used as an optimized time for further studies.

\subsection{Effect of reduction potential}

The effect of deposition potential on anodic peak current of $\mathrm{Hg}(\mathrm{II})$ was investigated by varying the potential in the range -0.1 to $-1.1 \mathrm{~V}$. It is observed from the figure that (Fig. 7d) the anodic peak current increases up to $-0.4 \mathrm{~V}$ and thereafter decreases. Therefore, potential of $-0.4 \mathrm{~V}$ was used as an optimum potential for the deposition of $\mathrm{Hg}$ (II) on the electrode surface.

Thus, $10 \mu \mathrm{L}$ volume of nanoparticles suspension, $\mathrm{pH} 7$, pre-concentration time of $5 \mathrm{~min}$ and deposition potential of $-0.4 \mathrm{~V}$ has been used as an optimum condition to generate caliberation graph for $\mathrm{Hg}$ (II) sensing.

\subsection{Calibration plot}

Calibration plot was constructed by measuring the peak currents after the addition of mercury ions (at each interval) into an electrochemical cell containing phosphate buffer $(\mathrm{pH} 8)$ under optimized conditions. The modified electrode exhibits linearity in the concentration window $10-600 \mathrm{nM}$. The correlation equations obtained were $\mathrm{I} / \mu \mathrm{A}=0.9305+0.0177$ $[\mathrm{Hg}(\mathrm{II})](\mathrm{nM})$ with a correlation coefficient of 0.978 . The peak current for the stripping of mercury ions was found to be increase linearly with increase in mercury concentration

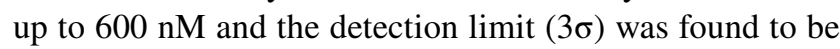
$2.25 \mathrm{nM}$ (Fig. $8 \mathrm{a}$ and b).

\subsection{Repeatability and reproducibility of the modified electrode}

The proposed interface has been examined for its reproducibility and repeatability in mercury quantification. Five different glassy carbon electrodes were chemically modified by drop casting method and used for mercury quantification at $300 \mathrm{nM}$ concentration level under optimized conditions. The peak currents of all these electrodes were well within $\pm 5 \%$ deviation indicating that the proposed interface processes has good reproducibility. Long term storage stability is essential feature for industrial applications. The long term storage stability of the $\mathrm{NiWO}_{4}$ nanoparticles modified electrode was studied over a period of 3 months by using single electrode at ambient temperature and optimized conditions. The measurements were carried out with successive intervals of 1 months. Figure 9 reveals that the analytical response of the modified electrode from the day of experiment to after 3 months has showed significant analytical
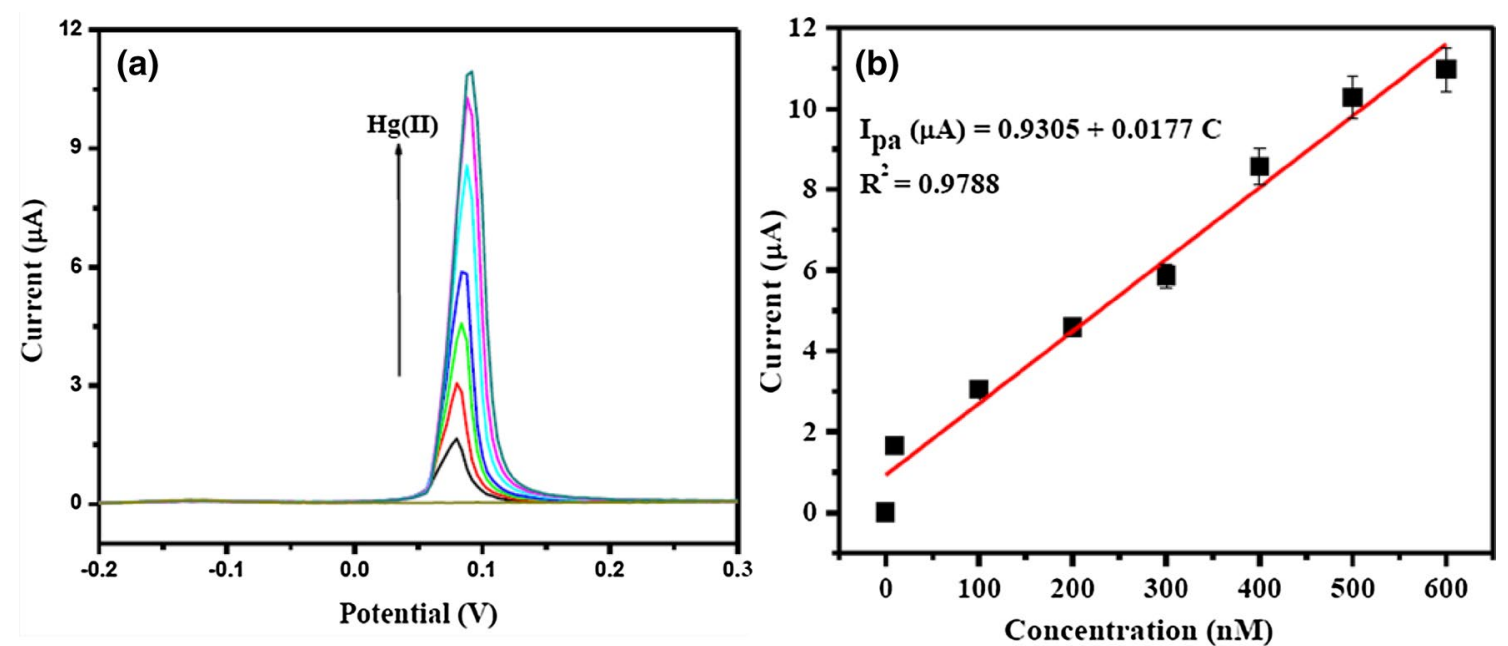

Fig. 8 a Overlaid differential pulse anodic stripping voltammograms and b Calibration plot with increasing addition of mercury ion (10$600 \mathrm{nM})$ under optimized conditions 
Fig. 9 Stability of the proposed sensor electrode over a period of three months

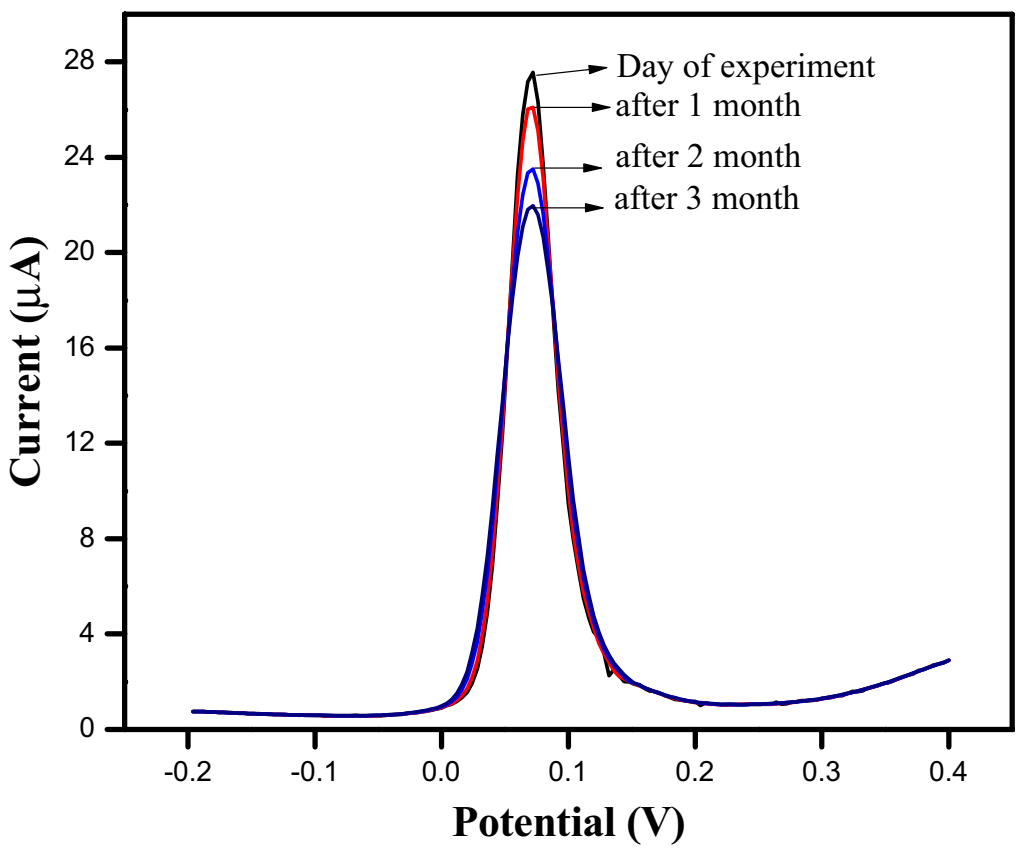

Table 1 Interference study

\begin{tabular}{ll}
\hline Interfering ions & $\begin{array}{l}\text { Tolerance } \\
\text { limit }(\mu \mathrm{M})\end{array}$ \\
\hline $\mathrm{Ag}^{+}, \mathrm{Fe}^{2+}, \mathrm{Ni}^{2+}, \mathrm{Co}^{2+}, \mathrm{Cu}^{2+}, \mathrm{Zn}^{2+}$ & 220 \\
$\mathrm{Na}^{+}, \mathrm{K}^{+}, \mathrm{Cs}^{+}$ & 530 \\
$\mathrm{Co}^{2+}, \mathrm{Ca}^{2+}, \mathrm{Mg}^{2+}, \mathrm{Ba}^{2+}, \mathrm{Be}^{2+}, \mathrm{Cr}^{3+}, \mathrm{Fe}^{3+}, \mathrm{As}^{3+}$ & 480 \\
$\mathrm{C}_{2} \mathrm{O}_{4}{ }^{2-}, \mathrm{CO}_{3}{ }^{2-}, \mathrm{Cl}^{-}, \mathrm{F}^{-}, \mathrm{I}^{-}, \mathrm{SO}_{4}{ }^{2-}, \mathrm{SO}_{3}{ }^{2-}, \mathrm{NO}_{2}{ }^{-}, \mathrm{NO}_{3}{ }^{-}$ & 350 \\
\hline
\end{tabular}

curves towards mercury ions with minute loss in the oxidative peak current, which shows the stability of the modified electrode as well as stability of modifier material.

\subsection{Interference study}

To investigate the efficiency of modified electrode in terms of selectivity towards electrochemical detection of mercury(II) ions in the presence of other interfering anion or cationic species was examined at $100 \mathrm{nM}$ mercury concentration. For the purpose of interference study, mercury ions were preconcentrated on $\mathrm{NiWO}_{4}$ nanoparticles modified electrode in presence of various cations and anions in the electrolyte solution. Table 1 show the tolerance limits of various cations and anions. It is obvious that, above tolerance limit, the foreign metal ions interfere and affect the quantity of preconcentration of mercury(II) by competing with the modifier functionalities and thus alters the peak currents originated by the stripping of mercury from the electrode interface. Thus, the obtained results suggest that the fabricated sensor exhibits least interference of various common species mentioned in the table. Therefore, the fabricated sensor has been successfully employed for the determination of mercury from a wide variety of environmental samples.

\subsection{Application study}

The analytical efficiency of $\mathrm{NiWO}_{4}$ nanoparticles modified sensor was evaluated by measuring the mercury levels present in real samples collected from industrial effluent such as chrome plating, lead acid batteries and textiles. The percentage of recovery was determined by the addition of known concentration of mercury to the electrochemical cell along with the originally present mercury in these samples (Table 2). The percentage recovery of added mercury were found to be $>98 \%$ indicating that the modified glassy carbon electrode can be used at trace level mercury quantification under optimized conditions and compared with other existing sensors (Table 2).

Further, the sensing performance of the $\mathrm{NiWO}_{4}$ nanoparticles modified sensor has been compared with the existing reports from literature as shown in Table 3. It is evident from Table 3 that the proposed sensor could be utilized for the real sample analysis effectively over the existing sensors.

\section{Conclusions}

A novel one step solution combustion method involving sucrose-nitrate decomposition has been proposed for the synthesis of $\mathrm{NiWO}_{4}$ nanoparticles with average particle size ranging from 15 to $35 \mathrm{~nm}$. TEM and SEM images show the formation of well dispersed nearly spherical 
Table 2 Application study

\begin{tabular}{lllllc}
\hline & Sample & $\begin{array}{l}\text { Originally present } \\
\text { mercury }(\mathrm{nM})\end{array}$ & $\begin{array}{l}\text { Added mer- } \\
\text { cury (nM) }\end{array}$ & $\begin{array}{l}\text { Total mer- } \\
\text { cury (nM) }\end{array}$ & Recover (\%) \\
\hline 1 & Tap water & ND & 30 & 30.5 & 100.32 \\
2 & Industrial water & 14.1 & 30 & 44 & 99.77 \\
3 & Lake water & 22 & 30 & 51.9 & 99.80 \\
4 & Chrome plating industrial effluent & 13.5 & 30 & 43.2 & 99.31 \\
5 & Textile industrial effluent & 21 & 30 & 50.8 & 98.60 \\
\hline
\end{tabular}

ND Not detected

Table 3 Comparison of proposed sensor with certain reported methods

\begin{tabular}{|c|c|c|c|c|c|}
\hline Electrode & Modifier molecule & Technique & Linear range (nM) & $\begin{array}{l}\text { Detection } \\
\text { limit }(\mathrm{nM}) \\
(\mathrm{LOD})\end{array}$ & Ref. \\
\hline GCE & Silica-SH & ASV & $10-100$ & 4.3 & [35] \\
\hline CPE & SAMMS-SH & ASV & $100-8000$ & 15 & [36] \\
\hline $\mathrm{Au}$ & Metallothionein & DPV & $150-300$ & 80 & [37] \\
\hline $\mathrm{Au}$ & MPS & DPV & $100-1000$ & 100 & [38] \\
\hline GCE & $\mathrm{Cu}_{7} \mathrm{~S}_{4}-\mathrm{Au} @ \mathrm{~S}-\mathrm{MoS}_{2}$ & SWASV & $360-3680$ & 190 & [39] \\
\hline GCE & $\mathrm{N}$-doped graphene & DPASV & $70-900$ & 50 & {$[40]$} \\
\hline CPE & $\begin{array}{l}\text { Magnetic nickel zinc } \\
\text { ferrite nanocomposite }\end{array}$ & SWASV & $40-2005$ & 08 & [41] \\
\hline SPE & Screen printed silver & LSV & $500-4500$ & 98 & {$[42]$} \\
\hline GCE & $\mathrm{CeO}_{2}$ & DPASV & $10-350$ & 3.3 & [43] \\
\hline GCE & $\begin{array}{l}\text { Ion imprinted poly- } \\
\text { meric nanobeads and } \\
\text { MWCNT }\end{array}$ & DPASV & $1.8-12.6$ & 5.0 & [44] \\
\hline GCE & $\mathrm{NiWO}_{4} \mathrm{Nanoparticles}$ & DPASV & $10-600$ & 2.25 & Present work \\
\hline
\end{tabular}

shaped nanoparticles. Specific surface area of the sample was found to be $\sim 16 \mathrm{~m}^{2} / \mathrm{g}$ and it exhibits type IV isotherm indicating mesoporous nature. Room temperature PL emission spectra shows a broad peak centered at $538 \mathrm{~nm}$. Further, the prepared $\mathrm{NiWO}_{4}$ nanoparticles were employed as electrode modifier for sensing of mercury in water samples. The results indicate that, the proposed modified electrode exhibits enhanced sensitivity and wide linearity in the concentration range $10-600 \mathrm{nM}$ with detection limit $2.25 \mathrm{nM}$ for mercury.

Acknowledgements The author, Eranjaneya H, acknowledges the CSIR, New Delhi, India, for awarding CSIR-SRF fellowship and Siddaramanna A, acknowledges the Science and Engineering Research Board (ECR/2017/ 000743) Government of India, for financial support.

\section{References}

1. T.-D. Nguyen, D. Mrabet, C.-T. T-T-D Vu, T.-O. Dinh, Do, CrystEngComm 13, 1450 (2011). https://doi.org/10.1039/c0ce00091d

2. Z. Nie, A. Petukhova, E. Kumacheva, Nat. Nanotechnol. Nat. Nanotechnol. 5, 15 (2010)

3. W. Yunjian, L. Li, G. Li, Appl. Surf. Sci. 393, 159-167 (2017)
4. S.M.M. Zawawi, R. Yahya, A. Hassan, H.N.M.E. Mahmud, M.N. Daud, Chem. Cent. J. 7, 80 (2013). https://doi. org/10.1186/1752-153x-7-80

5. H. Eranjaneya, G.T. Chandrappa, Trans. Indian Ceram. Soc. 75, 133-137 (2016)

6. W. Fan, M.A. Snyder, S. Kumar et al. (2008) Nat. Mater. 7, 984. https://doi.org/10.1038/nmat2302 https://www.nature.com/artic les/nmat2302\#supplementary-information

7. M.M. Mohamed, S.A. Ahmed, K.S. Khairou (2014) Appl. Catal. B 150, 63-73

8. R. Karthiga, B. Kavitha, M. Rajarajan, A. Suganthi, Mater. Sci. Semicond. Process. 40, 123 (2015). https://doi.org/10.1016/j. mssp.2015.05.037

9. S.M. El-Sheikh, M.M. Rashad, J. Cluster Sci. 26, 743 (2015). https://doi.org/10.1007/s10876-014-0735-Z

10. M.M.J. Sadiq, U.S. Shenoy, D.K. Bhat, J. Phys. Chem. Solids 109, 124 (2017). https://doi.org/10.1016/j.jpcs.2017.05.023

11. WH Organization (2011) World Health Organization, Geneva

12. A. Mirzaei, B. Hashemi, K. Janghorban, J. Mater. Sci. 27, 3109 (2016). https://doi.org/10.1007/s10854-015-4200-Z

13. Q. Bao, Z. Yang, Y. Song et al. (2018) J. Mater. Sci. https://doi. org/10.1007/s10854-018-0447-5

14. S.A. Prashanth, M. Pandurangappa, Mater. Lett. 185, 476 (2016). https://doi.org/10.1016/j.matlet.2016.09.010

15. R.K. Upadhyay, S. Deshmukh, S. Saha, A. Barman, S.S. Roy, J. Mater. Sci. 26, 7515 (2015). https://doi.org/10.1007/s1085 4-015-3387-3 
16. J. Li, L. Yan, H. Wang et al., J. Mater. Sci. 28, 3067 (2017). https ://doi.org/10.1007/s10854-016-5894-2

17. V. Gangaiah, P. Adarakatti, A. Siddaramanna, P. Malingappa, G. Thimmanna Chandrappa, Mater. Res. Express 4, 085039 (2017)

18. P.S. Adarakatti, M. Mahanthappa, E H.A. Siddaramanna, Electroanalysis 30, 1971-1982 (2018). https://doi.org/10.1002/ elan. 201800124

19. A. Siddaramanna, P.S. Adarakatti, H. Eranjaneya, L. Shreenivasa, Appl. Chem. Eng. 2, 1-11 (2018). https://doi.org/10.24294/jpd. v2i1.124

20. Z. Wu, L. Jiang, H. Chen, C. Xu, X. Wang, J. Mater. Sci. 23, 858 (2012). https://doi.org/10.1007/s10854-011-0506-7

21. S. Li, X. Gu, Y. Zhao, Y. Qiang, S. Zhang, J. Mater. Sci. 27, 8455 (2016). https://doi.org/10.1007/s10854-016-4860-3

22. S. Mani, V. Vediyappan, S.-M. Chen et al. Sci. Rep. 6, 24128 (2016). https://doi.org/10.1038/srep24128 https://www.natur e.com/articles/srep24128\#supplementary-information

23. L. Weber, U. Egli, J. Mater. Sci. 12, 1981 (1977). https://doi. org/10.1007/bf00561969

24. KT Jacob, J. Mater. Sci. 12, 1647 (1977). https://doi.org/10.1007/ bf00542815

25. A. Sen, P. Pramanik, J. Eur. Ceram. Soc. 21, 745 (2001). https:// doi.org/10.1016/S0955-2219(00)00265-X

26. J.H. Ryu, J.-W. Yoon, C.S. Lim, W.-C. Oh, K.B. Shim, Ceram. Int. 31, 883 (2005). https://doi.org/10.1016/j.ceramint.2004.09.015

27. R. Talebi, J. Mater. Sci. 27, 3565 (2016). https://doi.org/10.1007/ s10854-015-4192-8

28. O. Thoda, G. Xanthopoulou, G. Vekinis, A. Chroneos, Adv. Eng. Mater. 20, 1800047 (2018). https://doi.org/10.1002/adem.20180 0047 Doi

29. H. Eranjaneya, P.S. Adarakatti, A. Siddaramanna, P. Malingappa, G.T. Chandrappa, Mater. Sci. Semicond. Process. 86, 85 (2018). https://doi.org/10.1016/j.mssp.2018.06.020
30. C. Choodamani, N. Gp, A. Siddaramanna, D. Prasad, B.R. Basavanna, G.T. Chandrappa, J. Alloys Compd. 103-109 (2013)

31. S. Anusha, B.S. Anandakumar, M. Chakrabhavi Dhananjaya et al. RSC Adv. 4, 52181-52188 (2014)

32. H. Eranjaneya, G.T. Chandrappa, J. Sol-Gel. Sci. Technol. 85, 585 (2018). https://doi.org/10.1007/s10971-017-4545-2

33. N.J. Venkatesha, Y.S. Bhat, B.S. Jai Prakash, Appl. Catal. A 496, 51 (2015). https://doi.org/10.1016/j.apcata.2015.02.036

34. M.M. Mohamed, S.A. Ahmed, K.S. Khairou, Appl. Catal. B 150, 63-73 (2014). https://doi.org/10.1016/j.apcatb.2013.12.001

35. I. Cesarino, É.T.G. Cavalheiro, Electroanalysis 20, 2301 (2008). https://doi.org/10.1002/elan.200804325

36. W. Yantasee, Y. Lin, T.S. Zemanian, G.E. Fryxell, Analyst 128, 467 (2003). https://doi.org/10.1039/b300467h

37. H. Ju, D. Leech, J. Electroanal. Chem. 484, 150 (2000). https:// doi.org/10.1016/S0022-0728(00)00071-1

38. A. Walcarius, C. Delacôte, Anal. Chim. Acta 547, 3 (2005). https ://doi.org/10.1016/j.aca.2004.11.047

39. J. Cui, S. Xu, L. Wang, Sci. China Mater. 60, 352 (2017). https:// doi.org/10.1007/s40843-017-9019-4

40. H. Xing, J. Xu, X. Zhu et al., J. Electroanal. Chem. 760, 52 (2016). https://doi.org/10.1016/j.jelechem.2015.11.043

41. A. Afkhami, S. Sayari, F. Soltani-Felehgari, T. Madrakian, J. Iran. Chem. Soc. 12, 257 (2015). https://doi.org/10.1007/s1373 8-014-0480-0

42. M.-H. Chiu, J.-M. Zen, A.S. Kumar, D. Vasu, Y. Shih, Electroanalysis 20, 2265 (2008). https://doi.org/10.1002/elan.200804307 Doi

43. P.S. Adarakatti, V. Gangaiah, A. Siddaramanna Mater. Sci. Semicond. Process. 84: 157 (2018). https://doi.org/10.1016/j. mssp.2018.05.010

44. H.R. Rajabi, M. Roushani, M. Shamsipur, J. Electroanal. Chem. 693, 16 (2013). https://doi.org/10.1016/j.jelechem.2013.01.003 